\title{
Influence of Factor-Magnitude on Occupational Stress Among Agricultural Research Sector Employees in Kenya
}

\author{
Yusuf Wanjala Musi ${ }^{1}$, D. A. Ogolla ${ }^{2} \&$ D. L. Mutisya ${ }^{1}$ \\ ${ }^{1}$ Kenya Agricultural and Livestock Research Organization, Agricultural Mechanization Research Institute, \\ Katumani, Machakos, Kenya \\ ${ }^{2}$ College of Human Resource Management, Nairobi, Kenya \\ Correspondence: Yusuf Wanjala Musi, Kenya Agricultural and Livestock Research Organization, Agricultural \\ Mechanization Research Institute, Katumani, P.O. Box 340-90100, Machakos, Kenya. E-mail: \\ musiwanjala@yahoo.com
}

Received: June 7, 2019 Accepted: June 28, 2019 Online Published: August 29, 2019

doi:10.5539/jms.v9n2p73 URL: https://doi.org/10.5539/jms.v9n2p73

\begin{abstract}
Job dissatisfaction is inevitable in any work environment. The present study explored influence of factor-magnitude on occupational stress among agricultural research sector employees in Kenya. The study was carried out during the restructuring period of the agricultural research institutes in Kenya between 2013 and 2016 . The restructuring resulted in the formation of the Agricultural and Livestock Research Organization through the dissolution of four agricultural research institutes and merger of their operations and functions. The former institutes were: Coffee Research Foundation, Kenya Agricultural Research Institute, Kenya Sugar Research Foundation, and Tea Research Foundation. The 2922 employees of the organization were disillusioned during the four years of restructuring due to the loss of upkeep allowances among other benefits. A structured questionnaire was administered to 352 randomly selected employees in a survey carried out in 2016-2017. The study found that poor working conditions, effort-reward imbalance, job psychological distress, and lack of work motivation had significant $(p<0.05)$ effects on occupational stress. It was concluded that the on-going structural and remuneration changes would result in higher levels of job satisfaction and reduction in occupational stress among employees.
\end{abstract}

Keywords: work-conditions, work-motivation, effort-reward, psychological distress, Occupational stress, KALRO, agricultural sector, Kenya

\section{Introduction}

\subsection{Study Overview}

Occupational stress is the response of employees when presented with work pressure and demands that do not match their knowledge and abilities. This challenges their ability to cope with the situations. Stress that occurs due to the nature of work is termed as occupational stress. The terms work stress, job stress, or occupational stress are used interchangeably. Dollard et al. (2003) noted that the effects of economic globalization and rapid technological changes have resulted in increased workloads.

Kenya's Vision 2030 (GoK, 2007) recognizes the role of research in technology generation and creation of new knowledge, which are engines of national development. The government places great importance on value addition in crop and livestock as a means of raising rural household incomes as captured by the sector's driving strategy $(\mathrm{GoK}, 2009)$. To implement the second Medium Term Plan, the Kenya Government reformed the National Agricultural Research Systems through the creation of the Kenya Agricultural and Livestock Research Organization (KALRO). Its formation was aimed at restructuring agricultural and livestock research into a dynamic, innovative, responsive, and well-coordinated system driven by a shared vision and goal. The organization is a corporate body created under the Kenya Agricultural and Livestock Research Act of 2013. The Act establishes a suitable legal and institutional framework for the coordination of agricultural research in Kenya. Other core functions of KALRO include providing knowledge and information to farmers in diverse agro-ecological zones to enable them to make informed agricultural production decisions. KALRO also aims at improving incomes and food production. 


\subsection{Statement of the Problem}

KALRO's internal focus is to improve the work environment of workers serving in the public agricultural research sector. This is done through intensive research in relevant areas to come up with the appropriate recommendations. Stress is regarded to be one of the seven leading causes of death in the world; with cardiovascular disease being the leading cause for both men and women at workplace. Thus, national research employees are not exceptional to suffer from occupational stress based on the nature of work and treatment from the employer. For employees to perform well, the employment terms, training, working condition, motivation, and psychological comfort should be guaranteed. Furthermore, ergonomic, effort-reward, job security, relationship at work, and roles should be well defined and accompanied by commensurate remuneration. Finally, career advancement and other monetary and non-monetary aspects should be competitive.

Globally, South Africa is an example of a country that successfully restructured labour force after the apartheid regime. The restructuring aimed at re-addressing economic imbalances that caused employees stress, especially after considering what most of them underwent during the transition period (Bernstein, 1998). The situation in South Africa Agricultural Research Council corresponded to a racial division for a long time, and as a result of the apartheid legacy, the black workers suffered discrimination from their rich white peers (Vink, 2004; Le Roux, 2005). Thus, restructuring meant an equal opportunity to all races in South Africa rather than economic efficiency driven by professionalism (Vink \& Kirsten, 2000). However, the experience learnt was that black empowerment was not to be overemphasized because of the economic consequences of the privatization process that could occur (van Rooyen et al., 2010). In Kenya, the restructuring of the agriculture research sector could negatively affect productivity and level of job satisfaction of individual workers (Martin \& Schinke, 1998).

The study was guided by the following specific objectives:

i) To determine the effect of work conditions on occupational stress among employees of the agricultural research sector in Kenya.

ii) To establish the effect of work-reward imbalance on occupational stress among employees of the agricultural research sector in Kenya.

iii) To examine the effect of employee motivation on occupational stress among employees of the agricultural research sector in Kenya.

iv) To assess the effects of job psychological distress on occupational stress among employees of the agricultural research sector in Kenya.

\subsection{Justification and Related Hypotheses}

Stress is defined as a circumstance that threatens or is perceived to threaten one's wellbeing and hence affects one's mental coping abilities. The threat may be due to lack of physical safety, peace of mind, or many other things that one values at the workplace. Stress is also the arousal of mind and body in response to job demands like threats and opportunities in the workplace. Stress tends to spark images of traumatic crises. Stress is an everyday experience such as queuing on bank line to be paid one's salary, having car trouble, shopping for Christmas presents in the supermarket or staring at bills which are beyond one's ability to pay, and dealing with employees or employers industrial unrest. At a personal level, according to Sauter and Cooper (1989), stress can be related to depression, anxiety, general mental distress, and symptoms such as heart diseases, ulcers, and chronic pain.

The effort-reward imbalance model is one of the general theories of occupational stress that could be used to explain job-related stress among KALRO employees. This model emphasizes the link between self-regulatory needs of the worker and the social opportunity structure (Seigrist, 2001). An effort-rewarded imbalance is prevalent in-service occupations. Another accepted general theory of occupational stress is the demand control model. Siegrist (2001) stated that the demand control model visualizes a high level of psychological demand and low level of authority and skill utilization. These strain workers, leading to stress.

\subsection{Literature Review}

According to Boston University FSAO, causes for workplace conflict can be personality or style differences and personal problems such as substance abuse, childcare issues, and family problems. Organizational factors such as leadership, management, budget, and disagreement about core values can also contribute. Personal conflict also has another dimension such as relationship conflict. Relationship conflicts result from disagreements and incompatibilities among group members about personal issues that are not task related, such as social event's gossip, and world news (Barling \& Cooper, 2008). There are some other workplace conflicts caused by personal 
attributes that managers should understand some of which they can possibly help to remedy. Interpersonal conflict among people at work manifest through frequently noted stressors for employees (Keenan \& Newton, 1985; Liu, Spector, \& Shi, 2007). Conflict has been noted to be an indicator of the broader concept of workplace harassment (Bowling \& Beehr, 2006). Some of the critical factors leading to occupational stress in the public agriculture sector are presented in Figure 1. Research hypotheses were formulated from the identified factors from Figure 1.

Independent Variables

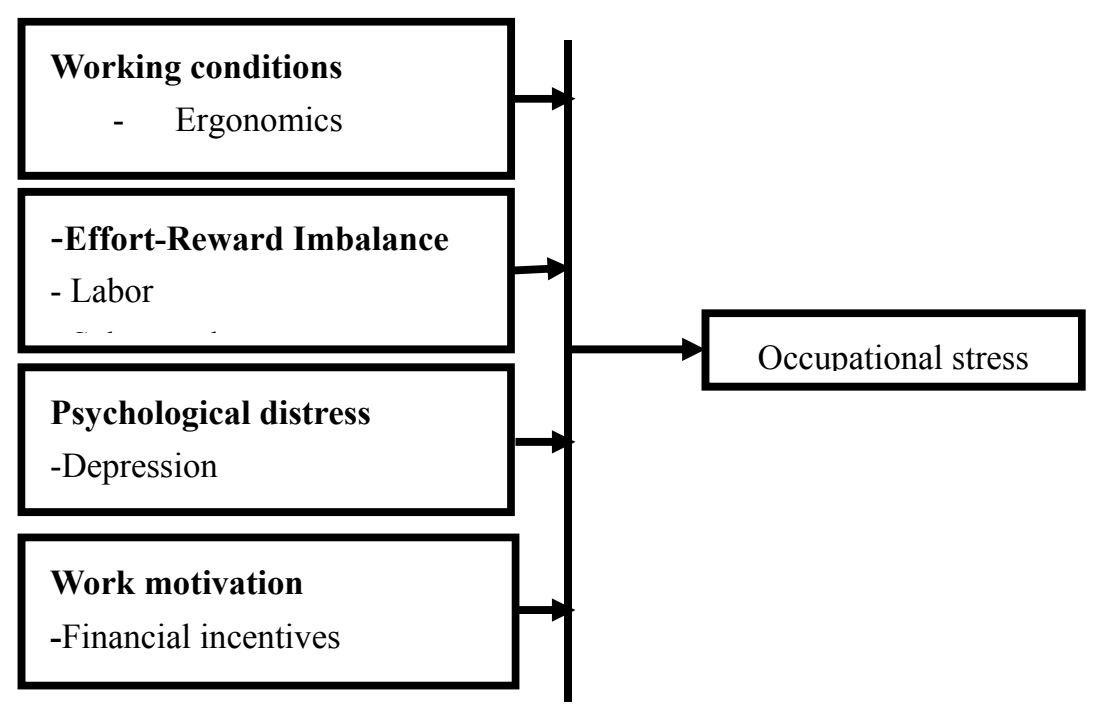

Figure 1. Conceptual framework

\section{Ho 1 Working conditions have a significant effect on occupational stress}

Studies from the field of environmental psychology indicate that there is a potential of physical work environment impacting negatively on the psychological health of employees. For example, community studies have suggested that issues such as noise and overcrowding result in symptoms of poor mental health (Taylor \& Repetti, 1997; Raffaello \& Maass, 2002). Medical studies have shown that patients respond to medication is enhanced when they are in rooms with windows overlooking natural scenes (Ulrich, 1984). Exposure to natural light argument also supports this concept (Choi, Beltran, \& Kim, 2012). Psychological health should be based on the presence of positive symptoms like wellbeing and the absence of negative symptoms (Hanebuth et al., 2006; Karihe, 2016). However, the more widely accepted term for concepts linked to psychological health e.g (stress, anxiety, and depression) is mental health.

\section{Ho 2 Effort-reward imbalance has a significant effect on occupational stress}

Several models of occupational stress have been formulated in an attempt to explain relationships between features of the working environment and employee wellbeing. One such model is the effort-reward imbalance model (Siegrist, 1996). The effort-reward imbalance model postulates that strain results from a perceived imbalance between the levels of effort employees put into their work and the rewards that they receive. The experience of effort-reward imbalance is considered to be more frequent in employees who are excessively committed (or over-committed) to their work. The effort-reward imbalance model; postulates that it is not merely effort (workload or other job demands that lead to strain) but also a perceived imbalance between the effort that employees believe they put into their jobs and the rewards that they receive (Siegrist, 1996). Rewards are distributed to employees by three transmitter elements of money (appropriate salary), esteem-sufficient respect and support, and security-career opportunities (Siegrist, 1996). Other studies have related effort-reward imbalance to less serious outcomes such as psychosomatic symptomatology, sleep disturbances, fatigue, problems of alcohol consumption, absenteeism and turnover (Siegrist, 2005; Hanebuth et al., 2006). Effort-reward imbalance is a form of inter-role conflict whereby the fulfillment of role demands emanating from one domain (work) that interferes with fulfilling role demands in another domain (Greenhaus \& Beutell, 1985). The present study aimed at expanding knowledge on how the effort-reward imbalance model affect employees of the agricultural research sector in Kenya. 


\section{Ho 3: Psychological distress has a significant effect on occupational stress}

Psychological health at the workplace is an essential subject of investigation because employees with a greater sense of psychological wellbeing are more likely to be productive. In addition, employees are likely to be creative and satisfied in their jobs compared to employees suffering from symptoms of psychological distress such as stress, anxiety, and depression. Furthermore, psychological distress in the workplace is associated with decreased job satisfaction and increased levels of absenteeism. Several factors, including psycho-social elements such as workload or lack of support from one's supervisor, can impact negatively on the psychological health of employees. Problems related to multiple roles such as decreased work performance, imbalance between work and family life and depression are a pressing problem for many workers. As pointed out by Hyland, Lee, and Mills (2015), the most prominent effect of mindfulness is a significant decrease in stress levels, and one of the most popular mindfulness interventions is mindfulness-based stress reduction. When it comes to psychological stress, desirable outcomes are both expected and documented for employees who adopt a mindful approach to work. There was a need to examine the reporting level on job psychological distress among agricultural research workers in Kenya.

\section{Ho 4 Work motivation has a significant effect on occupational stress}

Work motivation involves the ability to make somebody want to do something passionately. Research has shown that employee dedication in the workplace helps them to generate greater ownership over their work. Dedicated employees are also able to address or avoid stressful situations and achieve higher levels of wellbeing (Noblet \& LaMontagne, 2006).

Salary is the critical expectations that employees have when they begin employment. Policies and procedures that appear to discriminate between employees or are perceived to add value to some employees more than others are a common source of dissatisfaction and resentment. To get the best performance from employees, there is a need for some motivation beyond the monthly payment. According to Kinman et al. (2006) and Pabla (2012), sufficient motivation can create a productive workforce, but a lack of motivating factors can predispose employees to search for reasons for not giving their maximum effort at work. Therefore, employee motivation demands that effective remuneration programs are put in place to minimize stress. When employees perceive that they are not rewarded accordingly based on their efforts and expectations, they decrease their work performance. However, higher pay comes with the risk of increased operating cost to the firm (Certo, 2003). The study, therefore, hypothesized that occupational stress factors have a positive effect on the performance of employees in research institutions of Kenya.

\section{Methodology}

\subsection{Sample Selection}

The study adopted a stratified sampling technique for homogeneity of the population. Stratified random sampling technique enables subdivision of respondents into strata hence simplify data collection. The respondents were divided into strata based on departments in which they were formerly deployed and later selected randomly from the various departments in the various institutes (Table 1). According to Baird et al. (2007), a stratified sampling technique produces estimates of overall population parameters with greater precision and ensures that a more representative sample is derived from a relatively heterogeneous population. Stratification aims at reducing standard error by providing some control over variance. The study grouped the population into various strata according to the staff categories.

Table 1. Composition of employees of institutes that were merged to form KALRO

\begin{tabular}{llll}
\hline Institution & Category of Staff & Total & Sample size \\
\hline Kenya Agricultural Research Institute & Top level & 496 & 60 \\
& Middle Level & 998 & 62 \\
& Lower Level & 1014 & 40 \\
Coffee Research Foundation & Top level & 55 & 35 \\
& Middle Level & 69 & 30 \\
& Lower Level & 40 & 25 \\
Tea Research Foundation & Top level & 31 & 30 \\
& Middle Level & 50 & 20 \\
& Lower Level & 52 & 10 \\
Sugar Research Foundation & Top level & 25 & 20 \\
& Middle Level & 40 & 15 \\
& Lower Level & 52 & 5 \\
\hline Total & & 2922 & 352 \\
\hline
\end{tabular}


Fisher's formula was used to determine the appropriate sample size of the study. This was because the target population consisted of many units. The researchers assumed 95\% desired level of confidence, which was equivalent to standardized normal deviate value of 1.96, and an acceptable margin of error of 5\% (standard value of 0.05). Using Yamane (1967) formula, a sample size of 352 respondents was selected from the population and was arrived at (Table 2).

Table 2. Population indicative levels showing sample size and statistic confidence level

\begin{tabular}{lll}
\hline Population & Confidence level & Sampling error \\
\hline 2922 & $95 \%$ & 0.05 \\
\hline \multicolumn{2}{c}{} \\
$\qquad n=\frac{N}{1+N(\theta)^{2}}$
\end{tabular}

Where $\mathrm{N}=$ Population

$\mathrm{e}=$ Expected Error

Sample size $=\frac{2922}{1+2922(0.5)^{2}}=351.836$.

When rounded $=\mathbf{3 5 2}$

\subsection{Research Instruments}

The study employed a structured questionnaire to collect the primary data from the respondents. This meant that the study would be limited to the findings from the analysis of primary data. Mugenda and Mugenda (2008) observed that questionnaires were frequently used in quantitative social research. The questionnaire was used to capture demographic information of the respondents. More importantly, greater emphasis was on the instrument capturing data which were pertinent to both the study variables (independent and dependent variables) in line with the study objectives (Kothari, 2004). The questionnaire was both open and close-ended and on Likert scale; being simple, easy to follow, and in understandable language. The questionnaire was pre-tested on thirty-five people before being administered to ensure validity and reliability of the data collected as recommended by Kothari (2004).

In this research, descriptive study was employed. The explanation that underscored the influence of reported stress on employee performance was demonstrated by employees of the institutes; namely (CRF, KARI, KESREF and TRF). The researcher used multiple linear regression to calculate how many of the respondents affirmed that occupational stress (dependent variable) was as a result of the contributing factor variable (independent) change. The data obtained from the survey was fitted to the multiple linear regression model as per model of Greene (2012). This was to obtain the coefficient estimates of the factors contributing to the occupational stress to the employees. By convention, this model was represented as:

$$
y_{i}=\beta_{0}+\beta_{1} x_{1}+\mu
$$

Where $y_{i}$ represents the affirmation occupational stress level of the employees. Independent variables hypothesized to influence $y_{i}$ were represented by $x_{i}$ while $\beta_{1}$ represents the variable coefficients. Where applicable, $\beta_{0}$ would represent an intercept. The disturbance term, $\mu$, was assumed normally distributed with mean $=0$ and variance $\sigma 2=1$.

In this application, the empirical model was represented as:

$$
f=\beta_{0}+\beta_{1} f_{1}+\beta_{2} f_{2}+\beta_{3} f_{3}+\beta_{4} f_{4}+\mu
$$

Where $f=$ level of occupational stress factors; $f_{1}=$ poor working conditions; $f_{2}=$ effort-reward imbalance; $f_{3}=$ job psychological stress; and $f_{4}=$ lack of work motivation shown in Table 3 . 
Table 3. Variables expected to influence occupational stress level among agricultural research sector employees in Kenya

\begin{tabular}{lll}
\hline Variable & Description & $\begin{array}{l}\text { Expected relationship: independent } \\
\text { variable with the occupational stress }\end{array}$ \\
\hline Occupational stress factor & Dependent variable (number) \\
Poor working conditions, $f_{1}$ & No. employees affirming $(1=$ yes or $2=$ no $)$ & + \\
Effort-reward imbalance, $f_{2}$ & No. employees affirming $(1=$ yes or $2=$ no $)$ & + \\
Job-psychological stress, $f_{3}$ & No. employees affirming $(1=$ yes or $2=$ no $)$ & + \\
Lack of work motivation, $f_{4}$ & No. employees affirming $(1=$ yes or $2=$ no $)$ & + \\
\hline
\end{tabular}

\section{Results}

\subsection{Factor Effect}

A high number of respondents (82\%) reported that poor working conditions caused occupational stress as indicated in Table 4 . Similarly, $75 \%$ of the workers reported that effort-reward imbalance negatively affected their work esteem while $77 \%$ reported that they suffered psychological stress due to job-related stress. Overall, $82 \%$ of the workers reported lack of motivation for work. Different institutes had different scores of those who reported for each tested factor-magnitude.

Table 4. Response of employees on how different types of stress affected work performance $(\mathrm{N}=352)$

\begin{tabular}{llllll}
\hline Factor & Overall (\%) & KARI (\%) & CRF (\%) & TRF (\%) & KESREF (\%) \\
\hline Poor working conditions, $f_{1}$ & 82 & 38 & 20 & 14 & 10 \\
Effort-reward imbalance, $f_{2}$ & 75 & 35 & 19 & 12 & 9 \\
Job-psychological stress, $f_{3}$ & 77 & 34 & 20 & 13 & 10 \\
Lack work motivation, $f_{4}$ & 82 & 40 & 20 & 14 & 8 \\
\hline
\end{tabular}

Table 5 presents average number of employees' that reported unfavorable causes of occupational stress. KARI had statistically and significantly higher number of employees that reported highest level of occupational stress $(p<0.0001)$, followed by CRF. The TRF and KESREF reported the lowest occupational stress.

Table 5. Response of employees on how unfavorable factors affected their work place

\begin{tabular}{|c|c|c|c|c|c|c|c|c|c|c|c|}
\hline \multirow[b]{3}{*}{ Factor } & \multicolumn{8}{|c|}{ Institutes } & \multirow{3}{*}{$\begin{array}{l}\mathrm{N}=352 \\
R^{2}\end{array}$} & \multirow[b]{3}{*}{$F$-value } & \multirow[b]{3}{*}{$P$-value } \\
\hline & \multicolumn{2}{|c|}{ KARI } & \multicolumn{2}{|l|}{ CRF } & \multicolumn{2}{|l|}{ TRF } & \multicolumn{2}{|c|}{ KESREF } & & & \\
\hline & Mean & $S D$ & Mean & $S D$ & Mean & $S D$ & Mean & $S D$ & & & \\
\hline Poor working conditions, $f_{l}$ & $110^{\mathrm{A}}$ & 5.0 & $58.0^{\mathrm{B}}$ & 7.0 & $40.0^{\mathrm{C}}$ & 6.0 & $29.0^{\mathrm{C}}$ & 3.0 & 0.98 & 97.6 & $<0.0001$ \\
\hline Effort-reward imbalance, $f_{2}$ & $103.3^{\mathrm{A}}$ & 6.0 & $55.0^{\mathrm{B}}$ & 5.1 & $34.2^{\mathrm{C}}$ & 4.8 & $26.1^{\mathrm{C}}$ & 2.4 & 0.98 & 110.8 & $<0.0001$ \\
\hline Job-psychological stress, $f_{3}$ & $97.8^{\mathrm{A}}$ & 11.8 & $52.3^{\mathrm{B}}$ & 4.2 & $37.0^{\mathrm{BC}}$ & 3.3 & $22.0^{\mathrm{C}}$ & 3.2 & 0.94 & 35.9 & 0.0003 \\
\hline Lack of Work motivation, $f_{4}$ & $105.7^{\mathrm{A}}$ & 7.7 & $56.7^{\mathrm{B}}$ & 4.9 & $38.3^{\mathrm{C}}$ & 4.4 & $26.0^{\mathrm{C}}$ & 3.3 & 0.98 & 66.5 & $<0.0001$ \\
\hline
\end{tabular}

Note. Means within rows followed by different super transcribed letters denote significant $(P<0.05)$ difference of respondents at $5 \%$ level.

Factor regression results indicated that job psychological stress, effort-reward imbalance and lack of work motivation were the main causes of occupational stress in former institutes as indicated in Table 6 . The three factors significantly impacted stress level $(p<0.0001)$ among the workers. This leads to the rejection of the null hypothesis that factors $\left(f_{1}, f_{2}, f_{3}\right.$ and $\left.f_{4}\right)$ did not affect the overall stress levels of the agricultural research employees in Kenya.

Table 6. Factors affecting agricultural research employees that result to occupational stress

\begin{tabular}{llllll}
\hline Factor & SE & $\boldsymbol{t}$-value & $\boldsymbol{P}$-value & $\boldsymbol{R}^{\mathbf{2}}$ & Adj. $\boldsymbol{R}^{\mathbf{2}}$ \\
\hline Poor working conditions, $f_{1}$ & 0.036 & 5.54 & 0.0009 & 0.1571 & 0.1342 \\
Effort-reward imbalance, $f_{2}$ & 0.013 & 17.38 & $<0.0001$ & 0.9968 & 0.9345 \\
Job psychological stress, $f_{3}$ & 0.008 & 34.35 & $<0.0001$ & 0.9978 & 0.9324 \\
Lack of work motivation, $f_{4}$ & 0.033 & 8.61 & $<0.0001$ & 0.9973 & 0.9944 \\
\hline
\end{tabular}

Note. Variable regression against occupational stress (dependent variable) $(95 \%$ confidence level). 


\section{Discussion}

Since the inception of KALRO in 2013, some progress on actualization of the perceived objective had been put in place. The major problem that had persisted was diminishing funding from both the GOK and donor community. Lack of timely employee remuneration in line with job performance was also a born of contention. Kenya's Vision 2030 identified agriculture as the lead thrust for industrialization and development vehicle for the country; hence, the importance of KALRO to the country's development agenda. The study findings demonstrated a high level of stress among employees due to four factors. The results indicated that stress due to poor work conditions and work motivation was the highest occupational stress at $82 \%$, followed by effort-reward imbalance at $77 \%$ and related job psychological stress at $75 \%$ respectively. Occupational stress due to lack of work motivation was related to low pay and lack of recognition for effort-reward imbalance. The final factor that led to low work morale was psychological stress, where various perceptions on the part of the respondents were implied.

Worldwide, the literature indicates that stress levels at the workplace is mainly caused by neglect on the part of the employer to the employee's poor working conditions (Ahluwalia et al., 2004; Cavanagh \& Huston, 2006). This bring to the fore what ails most public institutions in Kenya and Africa at large. As reported verbally by some of the employees, lack of essential consumables for studies on animal disease management, lack of essential analytical input for laboratory and field experiments stressed the employees. Comparatively, international agricultural sector research institutions in Kenya including the International Livestock Research Institute (ILRI), the International Centre of Research in Agro-Forestry (ICRAF) and the International Centre of Insect Physiology and Ecology (ICIPE) had better facilities and better remuneration packages. Limited financial support was allocated to agricultural research in most African countries, leading to little or absence of innovation in agriculture and health research. This had also delayed industrialization and increased reliance on western countries for technological innovations.

Besides poor working conditions, the effort-reward imbalance was a significant factor associated with lack of job motivation. According to Nayak and Kehily (2008), psychological stress was accompanied by high blood pressure, digestive problems, ulcers, indigestion, palpitation, chest pains, skin disorder, muscle tension and headaches among others. This too was captured by the respondents during this study. This was the reverse in developed countries where management boards prioritized employee welfare. Similar scenarios occurred in public universities in Kenya and Africa. Little research was carried out in universities in Africa which are poorly equipped, leading to poor remuneration and subsequently low employee morale. The consequence had been a massive brain drain from such academic institutions. Workers in international institutions in Kenya enjoyed better pay packages and good working conditions than the national ones. The Kenya National Council of Science Technology and Innovation (NACOSTI) was mandated to fund research to university and public national research institutions in various development areas. Those who had benefitted from the funding reported inconsistent disbursement of funds, hence the poor flow of research activities and desired output.

According to Mairura (2009), counseling had positively significantly contributed to reducing stress among students. Though similar professional counseling could be applied to Kenya national research employees in the agricultural sector, a permanent solution would be to address the causes of occupational stress. This could reduce the negative experiences of the employees and positively impact on improved productivity (Fisher, 1994; Baird et al., 2007). The present research results were in agreement with Karihe (2016) who reported that part of stress reduction depended on how the organization supervisors or leaders assigned roles to their subordinates and how effectively those roles were assigned to enhance productivity. Working in a large, hierarchical, bureaucratic organization where employees had little control over their jobs could be very stressful (Kossek \& Oseki, 1998). Though this was not evaluated in this study, the concept remains the same.

Additionally, when there is a high concentration of assignments at work, excessive work or work that was outside one's capability, employees could get stressed and perform poorly (Carson et al., 2003). Nevertheless, this was not the target in the present study. Given that management supervisors held each employee accountable for their actions and duties, and for the quality of work they produced, role conflict that related to mismatched roles; and role ambiguity could explain the uncertainty of what was expected, lead to stress and eventually interfere with the performance of workers (Lee et al., 2015).

\section{Conclusion}

The results of this study indicated that workers from CRF, KARI, KESREF, and TRF that were merged into KALRO to form a significant segment of national researchers in the agricultural sector suffered substantial levels of occupational stress due to various negative factors at their work stations. This portrayed an organization in 
need of morale and motivation for efficient job performance. It was hoped that the on-going structural and remuneration changes could result in higher levels of job satisfaction, and increase technology in agricultural output for the benefit of local farmers with increased national wealth creation.

\section{Acknowledgement}

We acknowledge all respondents from the Coffee Research Institute, the Kenya Agricultural Research Institute, the Kenya Sugar Research Institute and the Tea Research Institute (which were merged to form the Kenya Agricultural and Livestock Research Organization [KALRO]) who responded to the questionnaire and sent in their contributions. We also thank the Director General of KALRO who allowed the author to carry out the research as part of the requirement in partial fulfilment for the professional qualification of College of Human Resource Management. Dr. Noah Wawire, the Director of KALRO's Agricultural Mechanization Research Institute for his critique on data evaluation. Prof. Roselyn Gakure, Prof. Elegwa Mukulu, Prof. Margaret Oloko and Dr. Elijah Gichuru provided technical critique that improved the paper quality. Finally, we thank Mr. Charles Langati and Mr. Lutomia Kweyu for their assistance in editorial.

\section{References}

Ahluwalia, I. B., Mack, K. A., \& Mokdad, A. (2004). Mental and physical distress and high-risk behaviors among reproductive-age women. Obstetrics and Gynecology, 104, 477-483. https://doi.org/10.1097/01.AOG.0000137920.58741.26

Baird, D., \& Fisher, M. O. (2007). Making and learning work: Utilizing mobile technology for active exploration, collaboration, assessment, and reflection in higher education. Journal of Education Technology Systems, $35(1), 3-30$.

Barling, J., \& Cooper, C. (2008). The SAGE Handbook of Organizational Behavior (p. 776). SAGE Publications Ltd. ISBN 9781412923859.

Bernstein, H. (1998). Social change in the South African countryside? Land and production, poverty and power. The Journal of Peasant Studies, 25(4), 1-32. https://doi.org/10.1080/03066159808438681

Bowling, N. A., \& Beehr, T. A. (2006). Workplace harassment from the victim's perspective: A Theoretical Model and Meta-Analysis. Journal of Applied Psychology, 91(5), 998-1012. https://doi.org/10.1037/0021-9010.91.5.998

Carson, E., Winefield, A., Waters, L., \& Kerr, L. (2003). Work for the dole: a pathway to self-esteem and employment commitment, or the road to frustration? Youth Studies Australia, 22(4), 19-26.

Cavanagh, S. E., \& Huston, A. C. (2006). Family instability and child well-being. Social Forces, 85, 551-581. https://doi.org/10.1353/sof.2006.0120

Certo, T. S. (2003). Influencing initial public offering investors with prestige: Signaling with Board Structures. The Academy of Management Review, 28(3), 432-446. https://doi.org/10.5465/amr.2003.10196754

Dollard, M. F., Dormann, C., Boyd, C. M., Winefield, H. R., \& Winefield, A. H. (2003). Unique aspects of stress in human service work. Australian Psychologist, 38(2), 84-91. https://doi.org/10.1080/00050060310001707087

Donaldson, G. (1994). Corporate restructuring: managing the change process from within (1st ed.). Harvard Business School Press, 658.16120/S.

Fisher, C. B. (1994). Reporting and referring research participants: Ethical challenges for investigators studying children and youth. Ethics and Behavior, 4, 87-95. https://doi.org/10.1207/s15327019eb0402_2

GoK. (2007). The Vision 2030: A competitive and prosperous Kenya. Ministry of Planning and National Development, Government of Kenya.

GoK. (2009). Agricultural Sector Development Strategy (ASDS). Agriculture Sector Ministries, Government of Kenya, Nairobi, Kenya.

Greene, W. H. (2012). Econometric Analysis (7th ed., p. 26).

Hanebuth, D., Meinel, M., \& Fischer, J. (2006). Health-related quality of life, psychosocial work conditions and absenteeism in an industrial sample of blue- and white-collar employees: a comparison of potential predictors. Journal of Occupational and Environmental Medicine, 48(1), 28-37. https://doi.org/10.1097/01.jom.0000195319.24750.f8

Hyland, P. K., Lee, R. A., \& Maura, J. M. (2015). A new approach to improving individual and organizational 
Performance. Industrial and Organizational Psychology, 8(4), 576-602. https://doi.org/10.1017/iop.2015.41

Karihe, J. N. (2016). Determinants of occupational stress affecting employees' performance in public universities in Kenya. Retrieved from http://hdl.handle.net/123456789/2099

Keenan, A., \& Newton, T. (1985). Stressful events, stressors and psychological strains in young professional engineers. Journal of Occupational Behaviour, 6(2), 151-156. https://doi.org/10.1002/job.4030060206

Kinman, G., Jones, F., \& Kinman, R. (2006). The well-being of the UK academy, 1998-2004. Quality of Higher Education, 12(1), 15-27. https://doi.org/10.1080/13538320600685081

Kossek, E. E., \& Ozeki, C. (1998). Work-family conflict, policies, and the job-life satisfaction relationship: A review and directions for organizational behavior Human Resources research. Journal of Applied Psychology, 83(2), 139-149. https://doi.org/10.1037//0021-9010.83.2.139

Kothari, C. R. (2004). Research methodology: Methods and techniques (2nd ed., p. 22). New Age International Publishers.

Le Roux, R. (2005). Agricultural workers: A historical and contemporary perspective, development and labour lonograph Series. The Institute of Development and Labour Law. University of Cape Town.

Mairura, L. (2009). Counselling for teenagers with chronic stress: A case of students in Nairobi day schools (p. 31). Nairobi, Kenya.

Martin, U., \& Schinke, S. P. (1998). Organizational and Individual Factors Influencing Job Satisfaction and Burnout of Mental Health Workers. Social Health Care, 28(2), 51-62. https://doi.org/10.1300/J010v28n02_04

Mugenda, M. O., \& Mugenda, A. (2008). Research methods: Qualitative and Quantitative Approaches (p. 35). Nairobi: African Centre for Technology Studies.

Nayak, A., \& Kehily, M. J. (2008). Gender, youth and culture: Young masculinities and meminities (p. 42). Palgrave Macmillan, Basingstoke, Hants. https://doi.org/10.1007/978-1-137-12214-8

Noblet, A., \& LaMontagne, D. A. (2006). The role of workplace health promotion in addressing job stress. Health Promotion International, 21(4), 346-353. https://doi.org/10.1093/heapro/dal029

Pabla, A. S. (2012). The management of otitis externa in UK general practice. European Archives of Oto-Rhino-Laryngology, 269(3), 753-756. https://doi.org/10.1007/s00405-011-1687-7

Raffaello, M., \& Maass, A. (2002). Chronic exposure to noise in industry: The effects on satisfaction, stress symptoms and company attachment. Environment and Behavior, 34(5), 651-671. https://doi.org/10.1177/0013916502034005005

Siegrist, J. (1996). Adverse health effects of high-effort/low-reward conditions. Journal of Occupational Health Psychology, 1, 27-41. https://doi.org/10.1037//1076-8998.1.1.27

Siegrist, J. (2005). Social reciprocity and health: New scientific evidence and policy implications. Psy-Choneuroendocrinology, 30(10), 1033-1038. https://doi.org/10.1016/j.psyneuen.2005.03.017

Taylor, S. E., Repetti, R. L., \& Seeman, T. E. (1997). Health psychology: What is an unhealthy environment and how does it get under the skin? Annual Review of Psychology, 48, 411-447. https://doi.org/10.1146/annurev.psych.48.1.411

Van Rooyen, J., Hobson, S., \& Kirsten, J. (2010). The contribution of agri-businesses to broad-based black economic empowerment in South African agriculture: Summary report and main findings. Agricultural Business Chamber. Pretoria.

Vink, N. (2004). The influence of policy on the roles of agriculture in South Africa. Development Southern Africa, 21(1), 155-177. https://doi.org/10.1080/0376835042000181462

Vink, N., \& Kirsten, J. (2000). Deregulation of agricultural marketing in South Africa: lessons learned. The Free Market Foundation, Monograph, 25, Sandton.

World Bank Africa Privatization Database. (2000). Retrieved August 24, 2000, from http://www4.worldbank.org/afr/database/afrpriv/p1query.cfm

Yamane, T. (1967). Statistics, an introductory analysis (2nd ed., p. 16). New York: Harper and Row.

Zimbardo, P. G., \& Leippe, M. R. (1991). The psychology attitude changes and social influence (1st ed.). 
McGraw-Hill, Inc.

\section{Copyrights}

Copyright for this article is retained by the author, with first publication rights granted to the journal.

This is an open-access article distributed under the terms and conditions of the Creative Commons Attribution license (http://creativecommons.org/licenses/by/4.0/). 